\title{
Anesthesia, sex and miscarriage history may influence the association between cesarean delivery and autism spectrum disorder
}

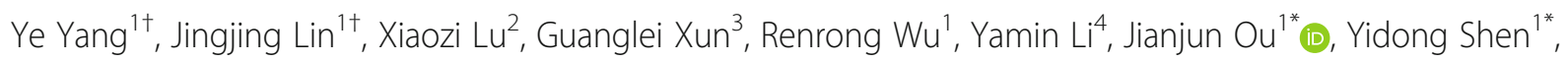
Kun $\mathrm{Xia}^{5}$ and Jingping Zhao ${ }^{1}$

\begin{abstract}
Background: To explore the association between cesarean section (CS) and risk of autism spectrum disorder (ASD), and evaluate the possible factors influencing this association.

Methods: In total, 950 patients diagnosed with ASD and 764 healthy controls were recruited in this study. Sociodemographic characteristics and prenatal, perinatal, and neonatal characteristics were compared between the two groups. Univariate and multivariable conditional logistic regression analyses were applied to adjust for confounders. Further stratified analyses based on sex and miscarriage history were similarly performed to explore the factors influencing the association between CS and ASD.

Results: CS was evidently associated with an elevated risk of ASD (adjusted odds ratio [aOR] $=1.606,95 \%$ confidence interval $(C I)=1.311-1.969)$. Unlike regional anesthesia $(R A)$, only CS performed under general anesthesia (GA) consistently elevated the risk of $\mathrm{ASD}(\mathrm{aOR}=1.887,95 \% \mathrm{Cl}=1.273-2.798)$ in females and males in further stratified analysis. The risk of children suffering from ASD following emergency CS was apparently increased in males (aOR $=2.390,95 \% \mathrm{Cl}=1.392-5.207$ ), whereas a higher risk of ASD was observed among voluntary CS and indicated CS subgroups $(\mathrm{aOR}=2.167,95 \% \mathrm{Cl}=1.094-4.291 ; \mathrm{aOR}=2.919,95 \% \mathrm{Cl}=1.789-4.765$, respectively) in females. Moreover, the interaction term of CS and past miscarriage history $(\beta=-0.68$, Wald $x 2=7.5, \mathrm{df}=1, p=$ 0.006)) was similarly defined as influencing ASD.

Conclusions: The exposure of children to GA during CS may explain the possible/emerging association between CS and ASD. In addition, sex and miscarriage history could equally be factors influencing the association between CS and ASD.
\end{abstract}

Keywords: Autism spectrum disorder, Cesarean section, Anesthesia, Sex, Miscarriage history

\footnotetext{
*Correspondence: oujianjun@csu.edu.cn; shenyidong1987@csu.edu.cn

${ }^{\dagger}$ Ye Yang and Jingjing Lin contributed equally to this work.

${ }^{1}$ National Clinical Research Center for Mental Disorders, Department of Psychiatry, and China National Technology Institute on Mental Disorders, The Second Xiangya Hospital of Central South University, Changsha 410011, Hunan, China

Full list of author information is available at the end of the article
}

(c) The Author(s). 2021 Open Access This article is licensed under a Creative Commons Attribution 4.0 International License, which permits use, sharing, adaptation, distribution and reproduction in any medium or format, as long as you give appropriate credit to the original author(s) and the source, provide a link to the Creative Commons licence, and indicate if changes were made. The images or other third party material in this article are included in the article's Creative Commons licence, unless indicated otherwise in a credit line to the material. If material is not included in the article's Creative Commons licence and your intended use is not permitted by statutory regulation or exceeds the permitted use, you will need to obtain permission directly from the copyright holder. To view a copy of this licence, visit http://creativecommons.org/licenses/by/4.0/ The Creative Commons Public Domain Dedication waiver (http://creativecommons.org/publicdomain/zero/1.0/) applies to the data made available in this article, unless otherwise stated in a credit line to the data. 


\section{Background}

Autism spectrum disorder (ASD) is a neurodevelopmental disorder in which the exact mechanism remains unclear and is characterized by impairment in social communication, alongside restricted interest and repetitive behaviors [1]. ASD has been of general concern globally, with a substantial increase in prevalence in recent decades [2]. Although ASD is highly genetic [3], there is evidence suggesting the involvement of numerous prenatal and perinatal factors in its development [3-7]. Among all gestational and obstetric risk factors of ASD, accumulated evidence suggests an association between cesarean section (CS) and ASD which is worrisome given the dramatically increasing trend in CS implementation in numerous countries [8, 9]. A recent metaanalysis demonstrated that a $23 \%$ increase in the risk of ASD was associated with CS compared to vaginal delivery [10]. Even though previous studies have reported that CS is not a risk factor for ASD [11, 12], most studies have reached a consistent conclusion [13, 14]. The incidence of CS is increasing globally, with an evaluated annual increase of $4 \%$ [15]. Surprisingly, the incidence of CS has increased rapidly in China over the past decade, with a current national rate of approximately 40\% [16]. It is becoming increasingly important to fully understand the association between CS and ASD.

The CS is a surgical procedure of delivering a baby to prevent a risk to the health of the mother or baby accompanied by vaginal delivery. Emergency CS is usually performed in an urgent situation due to complications, such as fetal distress which could occur spontaneously [17]. On the contrary, indicated CS (planned or elective CS) is scheduled beforehand and is mostly necessary for obstetric or medical indications such as multiple gestations, suspected macrosomia, or pre-existing obstetric conditions [18]. Nevertheless, in some countries, CS is implemented in a minority of the women, only on maternal request without medical indications (voluntary CS) [19]. Although CS is a relatively safe method compared to vaginal delivery, it has previously been linked to adverse health outcomes in newborns [20-22]. CS may directly and indirectly affect neurodevelopment, as well as cognitive outcomes [23]. Indirect influence could occur via established correlations between CS and negative outcomes on child health, that is associated with neurodevelopment, including disturbed gut microbiota and changes in stress response, among others [24, 25]. The existing evidence suggests that there is a significant correlation between CS and neurodevelopmental disorders, including ASD and attention deficit hyperactivity disorder (ADHD) [10, 26].

Although the association between CS and ASD has been established in several previous studies, the effect size is heterogeneous when allowing for the adjustment for different confounding factors [27, 28]. Data from previous studies have reported the risks of ASD in children following indicated CS and emergency CS were nearly identical compared with vaginal delivery; however, voluntary CS was not included by existing studies [14, 29]. Contradictory research has suggested that indicated and emergency CS are related to different indications and thus may be associated with differential neurodevelopment process [30]. Alternatively, the observed association may be due to the inclusion of more complete types of surgery indications in the analysis, considering that other confounding factors were controlled.

Emerging evidence has suggested an association between the types of anesthesia and risk of ASD development $[14,31]$. CSs are usually performed under general anesthesia (GA) or regional anesthesia (RA); however, $\mathrm{RA}$ is more frequently used because GA increases the complications of CS [32, 33]. Exposing the premature brains of the fetuses to obstetric anesthesia can result in histopathological damage, which can affect brain development $[34,35]$. The exposure of mothers to GA during labor was significantly associated with higher risk of ASD [14, 31]. On the contrary, inconsistent results have shown that the early exposure of children to anesthesia in the uterus, first 2 years of life, or afterwards is not associated with a higher risk of ASD [36]. Given the contradiction among the conclusions of various research, the susceptibility of a fetus to ASD subjected to obstetric anesthesia during CS requires further exploration.

There could be variation in the observed correlation based on concomitant confounding factors or confounding by indications; this indicates that ASD may be related to the indications and concomitant confounding factors of ASD, rather than the surgical procedure [10]. Considering that different types of CS are accompanied by heterogeneous and complex confounding factors, understanding the risk of ASD among different types of CS is crucial for the early detection and prevention of ASD. Therefore, this study aimed to explore the correlation between different types of CS and ASD, while taking various prenatal and perinatal confounders into account, based on data from a large retrospective case-control study that included comprehensive clinical data on the pregnancy and birth of these children.

\section{Methods}

\section{Subjects}

This study was conducted following the recommended guidelines prescribed by the Second Xiangya Hospital Ethics Committee. All subjects gave written informed consent following the Declaration of Helsinki. In this case-control study, both cases and controls were ascertained from two-stage data collections from training centers and special education schools across the country. 
The first and second stage recruitment of subjects and data collection were performed from 2012 to 2016 and 20162018, respectively. The data collection was conducted in two stages because scale entries were further refined and more detailed gestational and obstetric confounding factors were included in the second stage. Subjects in the first stage who were diagnosed with Autistic Disorder or Pervasive Developmental Disorder - Not otherwise specified (PDDNOS) in accordance with the criteria established in the Diagnostic and Statistical Manual of Mental Disorders Fourth Edition (DSM- IV) were eligible for this study. These diseases, as mentioned earlier, fulfilled the diagnostic criteria of DSM- 5 for ASD. For subjects in the second stage, the diagnostic criteria of the Diagnostic and Statistical Manual of Mental Disorders Fourth Edition (DSM-5) was employed. Children with ASD following the criteria set out in DSM-5 were enrolled in this study. ASD was diagnosed by two experienced pediatric psychiatrists, according to DSM- IV or DSM- 5 criteria.

Children with severe physical diseases such as congenital heart disease or hematological diseases, or the first diagnosis is other psychiatric disorders, such as schizophrenia or Intellectual Disability, were excluded. Autistic patients with chromosomal abnormalities, such as Fragile $\mathrm{X}$ syndrome and Down's syndrome, were equally excluded. Since previous studies have shown that gestational age may be a significant influencing factor of ASD, newborns of gestational age $<37$ or $>42$ weeks were excluded from this study. Similarly, patients who underwent assisted delivery, including the use of forceps, vacuum, and oxytocin were excluded from this study.
Controls were recruited from neighborhood kindergartens and in the same city. Typically developing children were recruited by adapting a survey questionnaire that include basic information and a screening test for preliminary screening of neurological or neurodevelopment disorder. Other exclusion criteria are similar to those in the autism group. Five hundred fifty-one patients and 874 healthy controls were recruited in the first stage, while 739 patients and 64 healthy controls were recruited in the second stage. In total, 1290 patients and 938 healthy controls were recruited in current study. However, 174 controls and 340 children with autism were excluded from analysis due to missing data. Ultimately, 950 children with autism and 764 controls were enrolled for the subsequent data analyses, the research process is shown in Fig. 1.

\section{Data collection}

Details of data collection have been described in a previously published study [37]. In summary, data on the subjects were collected from a general socio-demographic questionnaire administered to the parents/guardians of all ASD cases and controls during enrollment. In addition to demographic, clinical, and behavioral data of the subjects, prenatal, perinatal and neonatal variables for both cases and controls were collected in this study. Behavioral data were evaluated by Social Responsiveness Scale (SRS). Prenatal characteristics included parental age, maternal childbearing age, and past miscarriage history. Perinatal characteristics of the enrolled children included parity number, gravity number, past miscarriage

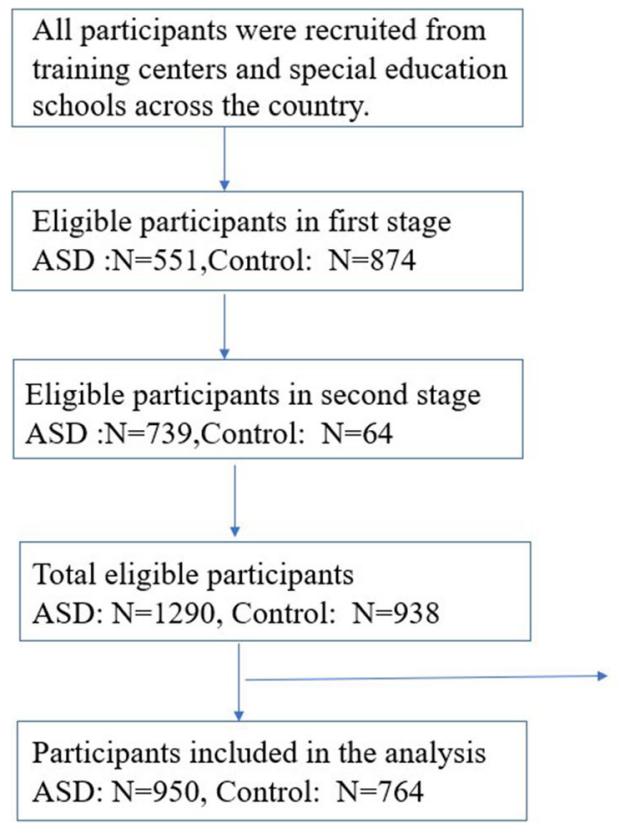

174 controls and 340 ASD were excluded from analysis due to missing data

Fig. 1 Flowchart of participation in the study 
history, threatened abortion, mode of delivery (CS vs. vaginal delivery), surgery indication (emergency CS, voluntary CS and indicated CS) and types of anesthesia (RA vs. GA), which were considered as independent variables for this analysis. Infant variables for both cases and controls included sex, age and birth weight.

\section{Statistical analysis}

Data analyses were performed using SPSS version 18 (Armonk, NY, USA). The socio-demographic characteristics, as well as the correlations of CS and maternal, perinatal, and neonatal characteristics with the risk of ASD, were assessed via appropriate bivariate statistical tests. In the event data did not follow a normal distribution, we used a Mann-Whitney test. We used a $t$-test when the data were normally distributed. In addition, categorical variables were compared using the chisquare or Fisher exact tests. The univariate conditional logistic regression models were used in the assessment of the univariable association of various prenatal, perinatal and neonatal characteristics with ASD. Further multivariate conditional logistic regression models were conducted to evaluate the adjusted effect of CS on the risk of ASD (compared to vaginal deliveries). The variables that were obviously correlated with ASD ( $p$-value $<0.05$ ) were considered potential confounders and included in this model. Subgroup analyses were performed to assess the influence of various CS types on the risk of ASD. CS deliveries were stratified to different types according to the type of anesthesia and the indications for CS. The associations were analyzed by sex separately to evaluate the sex-specific relationship between CS and ASD and to remove the effects of an unbalanced sex ratio. Similarly, the analysis was separately conducted according to the history of miscarriage because it is a significant risk factor for ASD in current studies [38].

\section{Results}

In total, 950 ASD cases and 764 subjects (as controls) were included in this study. The median age of the ASD cases and controls were 4.0 and 4.8 years, respectively. Majority of the ASD cases were male (792/158), whereas the sex distribution in the controls was balanced (407/ 357). Table 1 shows the association between prenatal, perinatal, and infant characteristics and ASD risk, respectively. CS was correlated with the risk of ASD $(p<$ 0.001). Apart from CS, other variables that were associated with the risk of ASD included: parity number $(p<$ $0.001)$, history of miscarriage $(p<0.001)$ and infant's weight at birth $(p=0.001)$. Behavioral characteristics of the samples are presented in Table 2 .

Univariate conditional logistic regression analyses revealed that CS was significantly associated with ASD (adjusted odds ratio $[\mathrm{aOR}]=1.606 ; 95 \%$ confidence interval $[\mathrm{CI}]=1.311-1.969$ ). This association was equally observed between CS and the parity number, and past history of miscarriage. Further multivariate conditional logistic regression models revealed an association between the risk of CS delivery (vs. vaginal delivery) and ASD. After adjusting for prenatal, perinatal or neonatal confounding factors that were associated with ASD $(p<$ 0.05 ) in this study (Table 3 ), the results similarly indicated a significant association between CS and ASD $(\mathrm{aOR}=1.573 ; 95 \% \mathrm{CI}=1.241-1.992)$. While parity number was not a risk factor for ASD as demonstrated by univariate conditional logistic regression analyses, multiple regression analyses interestingly identified the interaction term of CS and history of miscarriage $(\beta=-0.68$, Wald $\mathrm{X}^{2}=7.5, \mathrm{df}=1, p=0.006$ ) as an influencing factor for ASD.

\section{Subgroup analysis}

In order to further explore the mechanism underlying the association between CS and ASD, the sample was

Table 1 Prenatal, perinatal, and infant characteristics of cases and control subjects

\begin{tabular}{|c|c|c|c|}
\hline Variables & $\begin{array}{l}\text { ASD } \\
(N=950)\end{array}$ & $\begin{array}{l}\text { Control } \\
(N=764)\end{array}$ & $P$ \\
\hline \multicolumn{4}{|l|}{ Maternal and prenatal characteristics, N (\%) } \\
\hline Mother's age at birth (Years) & $28.0(25.9,30.0)$ & $28.0(25.0,30.3)$ & 0.812 \\
\hline Parity number & $1(1.2)$ & $1(1.2)$ & $<0.001$ \\
\hline Gravity number & $1(1.1)$ & $1(1.1)$ & 0.828 \\
\hline Past miscarriage history & $315(34.4)$ & $119(18.1)$ & $<0.001$ \\
\hline Threatened abortion & $127(13.6)$ & 79 (10.6) & 0.072 \\
\hline \multicolumn{4}{|l|}{ Labor and perinatal characteristics, N (\%) } \\
\hline Cesarean section, Infant characteristics & $491(51.7)$ & $301(39.4)$ & $<0.001$ \\
\hline Infant's weight at birth (kg), Median (IQR) & $3.5(3.2,3.9)$ & $3.4(3.1,3.8)$ & 0.001 \\
\hline
\end{tabular}

Bold values are statistically significant associations ( $p$-value $<0.05$ ) ASD Autism spectrum disorder

Values are presented as median (IQR [interquartile range]) 
Table 2 Behavioral characteristics of parents and children

\begin{tabular}{lll}
\hline SRS & $\begin{array}{l}\text { ASD } \\
(\boldsymbol{N}=\mathbf{9 5 0})\end{array}$ & \multicolumn{1}{c}{$\begin{array}{c}\text { Control } \\
(\boldsymbol{N}=\mathbf{7 6 4})\end{array}$} \\
\hline Total score, mean \pm SD (min, max) & $95.0 \pm 25.1(20.170)$ & $51.9 \pm 18.1(1,84)$ \\
Social awareness, mean \pm SD (min, max) & $13.6 \pm 3.6(1,24)$ & $5.0 \pm 2.7(0,17)$ \\
Social cognition, mean \pm SD (min, max) & $18.8 \pm 5.1(0,33)$ & $10.0 \pm 4.0(0,16)$ \\
Social communication, mean \pm SD (min, max) & $32.7 \pm 9.3(9,61)$ & $16.3 \pm 6.9(0,48)$ \\
Social motivation, mean \pm SD (min, max) & $15.8 \pm 4.9(1,31)$ & $9.3 \pm 3.8(0,17)$ \\
Autistic mannerisms, mean \pm SD (min, max) & $14.1 \pm 6.6(1,35)$ & $6.2 \pm 4.8(0,7)$ \\
\hline
\end{tabular}

SRS Social Responsiveness Scale

stratified according to different surgery indications and types of anesthesia; the same conditional logistic regression models were applied in these subgroups (Fig. 2). After adjusting for potential risks that were correlated with ASD, (Table 3), it was observed in the stratified analysis that a similar risk exists for ASD between voluntary CS and indicated CS $(\mathrm{aOR}=1.517,95 \% \mathrm{CI}=1.023-$ $2.249 ; \mathrm{aOR}=1.607,95 \% \mathrm{CI}=1.237-2.088$ respectively). On the contrary, emergency CS was associated with a higher risk than voluntary CS and indicated CS compared to vaginal deliveries $(\mathrm{aOR}=2.240,95 \% \mathrm{CI}=$ 1.418-3.541). Subsequently, CS was stratified according to the anesthesia regimen, and 51 subjects with no record of anesthesia were excluded from the analysis. This model revealed that CS performed under GA indicated a 1.8-fold increased risk of ASD compared with vaginal deliveries $(\mathrm{aOR}=1.887 ; 95 \% \mathrm{CI}=1.273-2.798)$. However, insignificant differences in the risk of ASD were observed between neonates delivered by CS under RA and those delivered vaginally $(p>0.05)$.

\section{Sex stratification analysis}

Given the unbalanced sex distribution in the ASD cases, separate analyses were conducted according to sex (Fig. 3), after controlling for potential risks. The risk of ASD among neonates delivered by CS compared with those delivered vaginally was approximately twice higher in females than males $(\mathrm{aOR}=2.565,95 \% \mathrm{CI}=1.676$ 3.926; $\mathrm{aOR}=1.368,95 \% \mathrm{CI}=1.045-1.792$, respectively). In males, the aOR of ASD following CS was elevated across the emergency subgroups $(\mathrm{aOR}=2.390,95 \% \mathrm{CI}=$
1.392-5.207). In addition, no risk of ASD was observed among voluntary CS and indicated CS (both $p>0.05$ ). The children delivered by CS under GA demonstrated a $44 \%$ higher risk of developing ASD than those delivered vaginally $(\mathrm{aOR}=1.447,95 \% \mathrm{CI}=0.914-2.289)$. Notably, this model indicated no statistical difference in the risk of ASD between children delivered by CS under RA and those delivered vaginally ( $p=0.966$ ).

Unlike males, a higher risk of ASD was observed among the voluntary CS and indicated CS subgroups $(\mathrm{aOR}=2.167 ; 95 \% \mathrm{CI}=1.094-4.291 ; \mathrm{aOR}=2.919 ; 95 \%$ $\mathrm{CI}=1.789-4.765$, respectively) in females. However, the analysis revealed no significant difference in the risk of developing ASD in the emergency CS subgroup compared to vaginal deliveries subgroup $(p>0.05)$. Similarly, an increased risk of ASD was correlated with CS under GA $(\mathrm{aOR}=3.588,95 \% \mathrm{CI}=1.757-7.327)$, unlike CS under $\operatorname{RA}(p>0.05)$, after adjusting for potential risks.

\section{Stratification analysis relative to miscarriage history}

Due to the interaction between miscarriage history and CS in the risk of developing ASD, further stratified analysis, according to miscarriage history, was similarly performed in this study (Fig. 4). Fifty-nine subjects with no record of miscarriage history were excluded in the analysis. Interestingly, CS was not significantly associated with the risk of ASD among subjects with a history of miscarriage $(p=0.999)$. In addition, further subgroup analysis equally revealed no significant association between different types of CS and ASD (all $p>0.05$ ). In line with the results above, CS is a significant risk factor for

Table 3 Univariate and multivariate analyses for the risk of ASD

\begin{tabular}{|c|c|c|c|c|}
\hline \multirow[t]{2}{*}{ Variable } & \multicolumn{2}{|l|}{ Univariate } & \multicolumn{2}{|l|}{ Multivariate } \\
\hline & $\begin{array}{l}\text { Adjusted OR } \\
(95 \% \mathrm{Cl})\end{array}$ & $P$-value & $\begin{array}{l}\text { Adjusted OR } \\
(95 \% \mathrm{Cl})\end{array}$ & $P$-value \\
\hline Parity number & $1.265(1.114-1.436)$ & $<0.001$ & $0.930(0.776-1.115)$ & 0.434 \\
\hline Past miscarriage history & 2.069 (1.579-2.679) & $<0.001$ & $2.262(1.501-3.410)$ & $<0.001$ \\
\hline Cesarean section & $1.606(1.311-1.969)$ & $<0.001$ & $1.573(1.241-1.992)$ & $<0.001$ \\
\hline Infant's weight at birth & $0.989(0.968-1.010)$ & 0.079 & $1.001(1.000-1.001)$ & 0.026 \\
\hline
\end{tabular}

Bold values are statistically significant associations ( $p$-value $<0.05$ )

$O R$ Odds ratio, $\mathrm{Cl}$ Confidence intervals 


\section{Adjusted OR (95\%Cl) P}

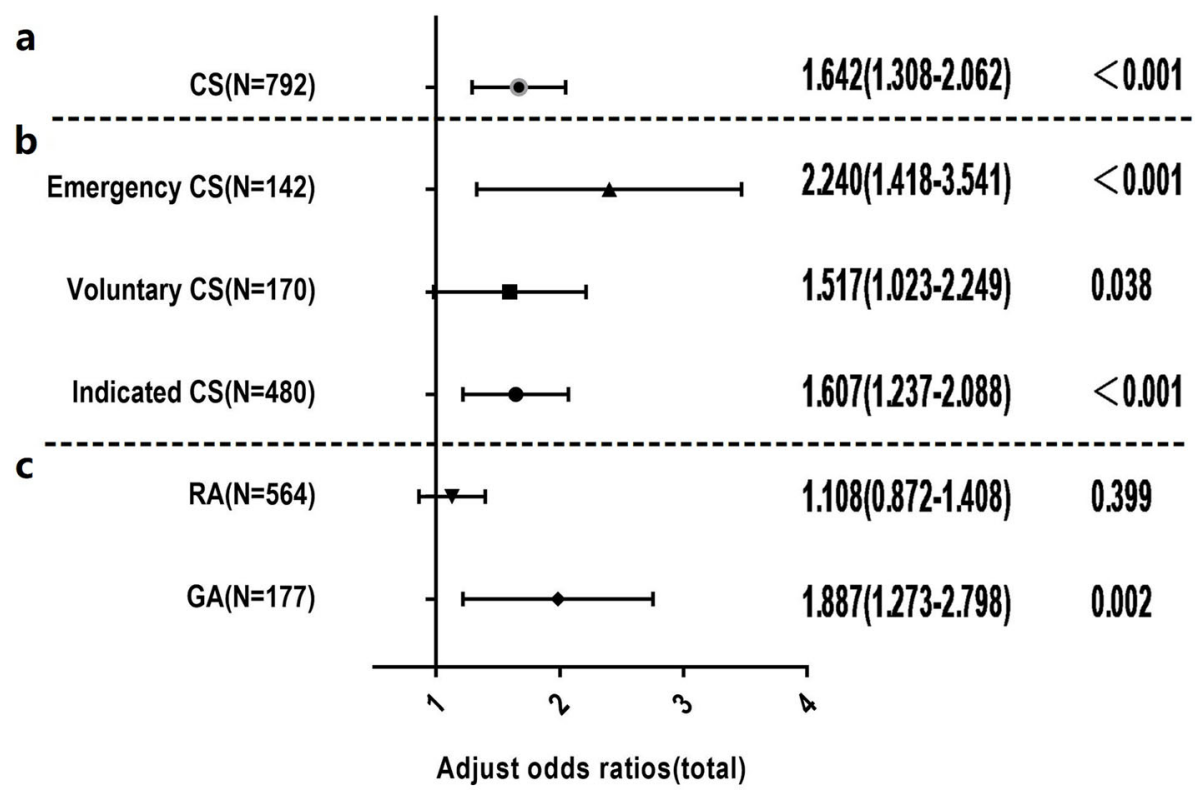

Fig. 2 a A forest plot of the association between cesarean section (CS) and Autism Spectrum Disorder (ASD) in total study samples; b Adjusted odds ratios and two-sided 95\% confidence intervals of ASD following CS compared with vaginal delivery in different anesthesia regimen subgroups (regional anesthesia [RA] vs. general anesthesia [GA]); c Adjusted odds ratios and two-sided 95\% confidence intervals of ASD following CS compared with vaginal delivery in different surgery indication subgroups (emergency CS, voluntary CS and indicated CS). Gray dashed horizontal lines separate the results of different stratification analyses. Adjusted odds ratio for CS was estimated from logistic regression after adjusting for confounding factors (e.g., parity number, past miscarriage history, subject's sex and age, and past miscarriage history* ${ }^{*} \mathrm{CS}$ ). Adjusted odds ratio for different surgery indication was adjusted for confounding factors (parity number, past miscarriage history, children's sex and age). Adjusted odds ratio for anesthesia regimen was adjusted for confounding factors (parity number, past miscarriage history, infant's weight and children's sex and age)

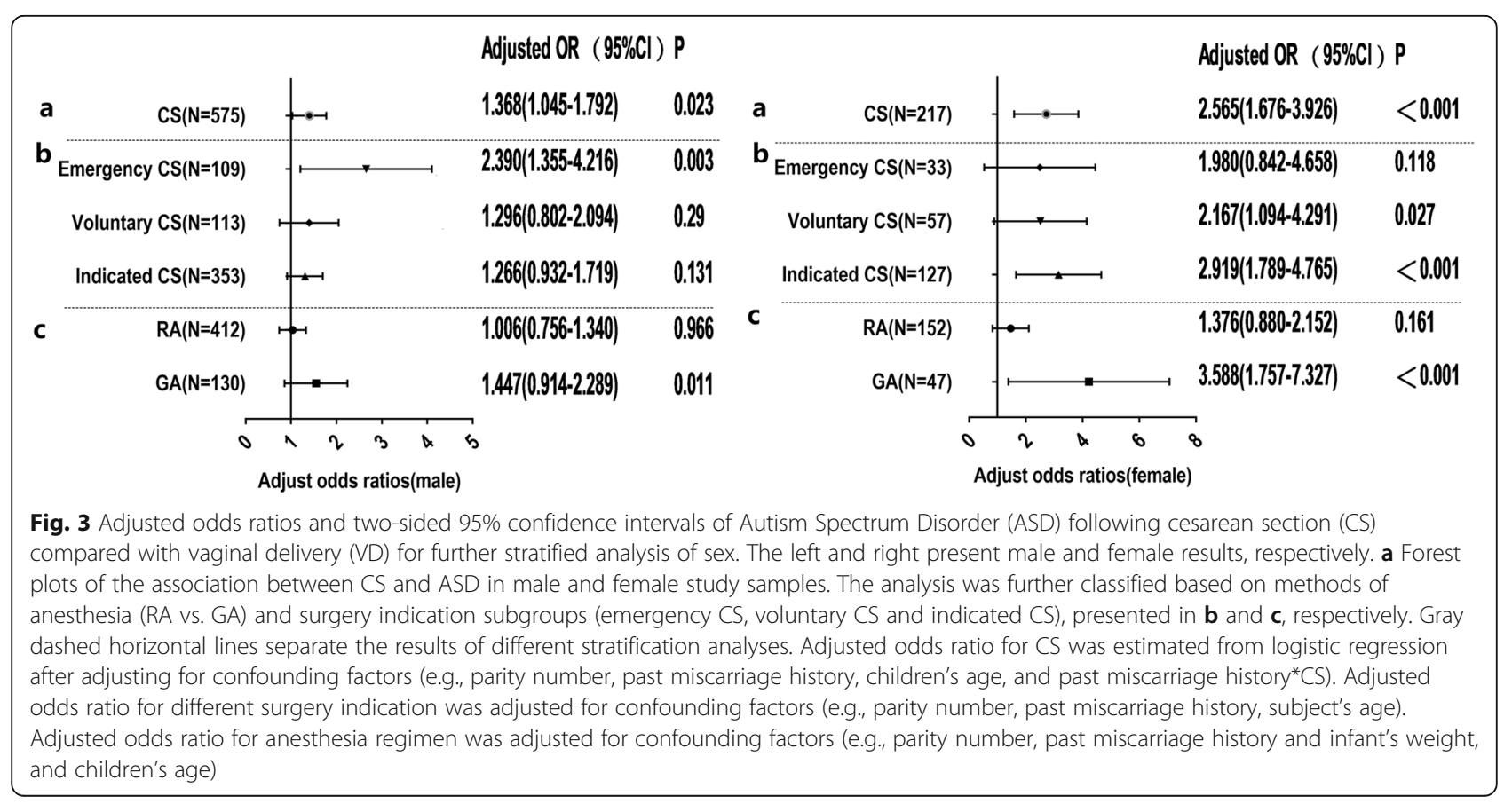




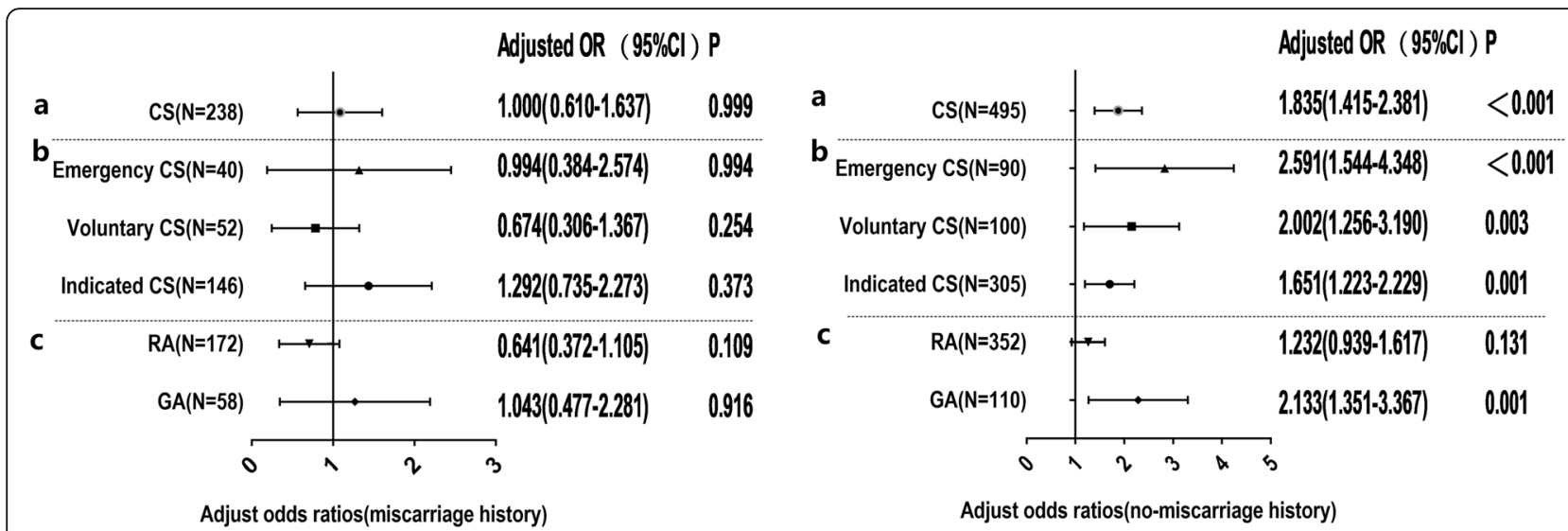

Fig. 4 Adjusted odds ratios and two-sided 95\% confidence intervals of Autism Spectrum Disorder (ASD) following cesarean section (CS) compared with vaginal delivery (VD) for further analysis of past miscarriage history. The left and right present the results of analysis with and without a history of miscarriage, respectively. a Forest plots of the association between CS and ASD in study samples with and without a history of miscarriage. The analysis was further classified based on methods of anesthesia (RA vs. GA) and different surgery indication subgroups (emergency CS, voluntary CS and indicated CS), presented in $\mathbf{b}$ and $\mathbf{c}$, respectively. Gray dashed horizontal lines separate the results of different stratification analyses. Each adjusted odds ratio was estimated from logistic regression after adjusting for confounding factors (parity number, gestational diabetes, infant's weight and children's sex, and age)

ASD in subjects without a history of miscarriage $(\mathrm{aOR}=$ $1.835,95 \% \mathrm{CI}=1.415-2.381)$. In addition, the OR of ASD risk following emergency CS $(\mathrm{aOR}=2.591,95 \%$ $\mathrm{CI}=1.544-4.348)$ versus vaginal delivery was obviously higher than indicated $\mathrm{CS}(\mathrm{aOR}=1.651,95 \% \mathrm{CI}=1.223-$ $2.229)$ and slightly higher than voluntary $\mathrm{CS}(\mathrm{aOR}=$ $2.002,95 \% \mathrm{CI}=1.256-3.190)$. The neonates delivered by CS performed under GA had approximately two times higher risk of suffering from ASD than those birthed by vaginal delivery $(\mathrm{aOR}=2.133,95 \% \mathrm{CI}=351-3.367)$. Similarly, no association was observed between ASD and CS performed under RA $(p>0)$.

\section{Discussion}

This study demonstrated that the correlation between CS and ASD is exclusive to CSs performed under GA, with an evident heterogeneity in different surgical indications and sex. In addition, CS may interact with miscarriage history to influence the development of ASD.

According to this study, delivery by CS was associated with a higher risk of ASD in children, even after adjusting the potential confounding factors. The result was supported by previous well-established observations that increased risk of ASD was associated with delivery by CS $[13,27,29]$. Further sex stratification analysis revealed a sex-biased ratio in the risk of developing ASD among births by CS, irrespective of the different surgical indications and method of anesthesia. The risk of ASD among females which was twice higher in children delivered by CS than in those delivered vaginally was consistent with several previous reports [14, 31]. Evidently, females were more sensitive to the long-term effects of CS than males. Therefore, further research is required to investigate the mechanisms underlying the observed sex-related distinctions in the risk of ASD among births by CS.

The results supported the original hypotheses that emergency CS is associated with a higher risk of ASD than voluntary CS and indicated CS, and the risk of ASD following indicated CS is slightly higher than the risk following voluntary CS. Consistent results were observed in previous studies that both indicated CS (elective CS or planned CS) and emergency CS were associated with an increased risk of ASD, contrary to this study [14, 29, 31]. These discrepancies may be attributed to the heterogeneity of subgroups relative to surgical indications employed in different studies, contrary to this study. Previous analysis included emergency CS and indicated CS (elective CS or planned CS), excluding voluntary CS. Considering this result, emergency CS may confer additional risk of ASD beyond risks associated with factors leading to CS among indicated CS and voluntary CS. This indicates that CS may exclusively exert an inherent risk on ASD, and there might be an induced risk from complex rather than unequal confounding factors from different CS surgical indications (not CS exclusively). Existing evidence supports these hypotheses; CS, whether planned or emergency, appears to be correlated with a complex mix of confounding factors equally related to ASD risk [39]. A sibling design study revealed that neither emergency CS nor elective CS was correlated with ASD after adjusting for familial confounding factors, indicating that the correlation may not have exclusively originated from CS; in addition, it suggests that potential unknown familial factors might explain the association between CS and ASD, which strongly supports our viewpoints. Concomitant prenatal 
or perinatal risk factors among children delivery by CS can vary with different surgery indications [30]. This indicates that underlying maternal or fetal indications for CS may be important risk factors of ASD.

In males, emergency CS were associated with an increased risk of ASD in comparison with vaginal delivery, which was consistent with the conclusion drawn from the result of the total study population. On the contrary, no association was observed between emergency CS and ASD in females; instead, both voluntary CS and indicated CS significantly increased the risk of ASD. The rationale behind these discrepancies is yet to be accurately clarified as previous stratified analysis regarding surgical indications is limited. It was speculated that different surgical indications may exert distinct impact on the risk of ASD between males and females. A complex interaction of surgical indications and sex plays a pivotal role in the development of ASD. In addition to the interaction' hypothesis, another explanation regarding these discrepancies is that the small sample size of female subjects made it difficult to draw accurate conclusions. Thus, the contribution of different surgical indications to the unequal risk of development of ASD among females relative to males require further exploration.

Another crucial finding is that CS performed under GA were related to a higher risk of ASD than CS under RA or vaginal delivery, following adjustments for potential confounders consistently between males and females in further analysis stratified by to sex. This finding is in accordance with previous research which reported a significantly higher risk among children who were delivered by CS under GA [14, 31]; however, this contradicted other research which reported no association between GA and ASD (Creagh et al. 2016). Nonetheless, this study was designed to investigate the association between exposure to GA and ASD across periods before, during, and after delivery, rather than the effect of GA performed during CS on the risk of ASD. This discrepancy could imply an interaction between the effects of anesthesia and CS on the risk of ASD. Similarly, in the stratification by sex, a stronger association was observed between ASD and females than males; the explanation for this difference may be attributed to the greater susceptibility of females to the long-term effects of GA than males. Increasing evidence from animal models and observational human research has supported the hypothesis that GA during delivery is associated with neurotoxicity, affecting later neurodevelopment [32, 40, 41]. Another possibility is that the reason behind the GA in pregnant women is a risk factor for ASD and may have nothing to do with the CS itself. GA was generally administered for bleeding emergencies and foetal distress $[42,43]$, and the complications associated with these emergencies may be risk factors for ASD. However, we did not further explore the reasons for the use of GA in pregnant women, so it is impossible to control these confounding factors. Although this study, as well as previous studies, have controlled the confounding factors as much as possible, the possibility of the contribution of certain undocumented confounding factors or GArelated situations to the correlations between GA and risk of ASD cannot be excluded. Certain risks which are inherent to CS cannot be completely excluded, given the observation from a previous study that CS is associated with neurodevelopmental impairment [44]. Thus, whether GA independently or in interaction with CS contributes to the development of ASD remains unclear.

A novel finding in this study is that an interaction between miscarriage history and CS contributes to ASD risk. Only one previous study has reported miscarriage as a specific risk factor of ADHD and ASD [38], which is inconsistent with a recent study, which was similar to ours, that revealed no association between recurrent miscarriage and ASD [14]. In addition, the sample size was insufficient to detect the association between ASD and miscarriage. This study reported that a higher risk of ASD was identified among subjects with miscarriage history compared to those without miscarriage history. Further, stratified analysis suggested that no association was observed between CS and ASD in the subjects with miscarriage history. On the contrary, in subjects without miscarriage history, the risk of ASD following CS was significantly higher compared to that in vaginal deliveries, indicating miscarriage history may exert a greater impact on the risk of ASD than CS; this can be attributed to the covering effect of miscarriage history on CS regarding the risk of ASD among subjects with miscarriage history. One possible explanation of the mechanism underlying the interaction between CS and ASD is that miscarriage may cause disturbed gut microbiota and stress response [45]. Thus, it was speculated that miscarriage history and CS could induce analogous ASD risk factors, even if they are heterogeneous in nature. This demonstrates that miscarriage history and CS may play a synergistic role in the development of ASD by inducing similar risk factors; this strongly supported the view that the observed association may be due to confounding by indication rather than the CS procedure itself. However, to our knowledge, none of the previous publications has revealed an interaction between CS and the miscarriage history; thus, the mechanism for this interaction needs to be further clarified.

This study has some limitations. Limited known prenatal and perinatal risk factors of ASD were detected in this study; therefore, sufficient potential confounders could not be adjusted in multivariate analysis, such as crying, color at birth, convulsions at birth and jaundice, especially APGAR index is not available in many families 
given the retrospective study. Consequently, the findings could have been influenced by potential unmeasured confounding factors. However, the CS is a major exposure factor and therefore unlikely to be seriously affected by this shortcoming. Next, the imbalance in sex distribution could have affected the accuracy of the research results, although further sex-specific analysis was conducted; the small sample size of female subjects limited the number of strata used in the subgroup analyses. In addition, a sibling analysis was not performed in this study, and we were unable to further adjust for familial confounding factors. All data obtained were selfreported. Therefore, the results may be influenced by potential recall bias and exposure misclassification. Nevertheless, the exposure factor (CS) is a dominant event and is therefore unlikely to be influenced by recall bias; in addition, it was sufficient to investigate most of the hypotheses. It is also worth mentioning that the only diagnostic criterion, DSM-4, was adopted in our study, and the failure to use ADOS is another shortcoming. Lastly, our study does not further explore the possible correlation between the CS and the level of autistic symptoms, and further exploratory studies are needed in the future.

\section{Conclusions}

Our current research shows that CS is associated with ASD; and CS performed under GA were related to a higher risk of ASD than CS under RA. The associations between different types of CS and ASD is influenced by sex and miscarriage history.

\section{Abbreviations}

CS: Cesarean section; GA: General anesthesia; RA: Regional anesthesia; ASD: Autism spectrum disorder; ADHD: Attention deficit hyperactivity disorder; OR: Odds ratio; aOR: Adjusted odds ratio; Cl: Confidence interval

\section{Acknowledgements}

We are grateful to the National Natural Science Foundation funded this study and thankful to data collectors, supervisors and study participants for their devoted time.

\section{Authors' contribution}

YY contributed to analysis and drafted the manuscript and $J L$ collected data. $\mathrm{XL}, \mathrm{GX}$ and $\mathrm{YL}$ helped evaluate subjects. YS design and critically revised the manuscript; JO contributed to conception and design and contributed to interpretation; RW and KX contributed to analysis and interpretation; JZ contributed to conception and design. All authors have read and approved the manuscript.

\section{Funding}

This work was supported by the National Natural Science Foundation of China $(<$ grant $81974217>[$ to $<J O>$ ] and $<$ grant $81901388>[$ to $<$ YS $>$ ]); Major Scientific and Technological Projects for collaborative prevention and control of birth defects in Hunan Province (<grant 2019SK1015 > [to < $\mathrm{JO}>\mathrm{]})$.The funders of the study had no role in study design, data collection, data analysis or interpretation or writing the report/manuscript.

\section{Availability of data and materials}

The datasets used are available from the corresponding author on reasonable request.

\section{Ethics approval and consent to participate}

This study was conducted following the recommended quidelines prescribed by the Second Xiangya Hospital Ethics Committee. The parents of all participants signed consent prior to participation and were allowed to stop the participation without prejudice.

\section{Consent for publication}

Not applicable.

\section{Competing interests}

The authors declare that they have no competing interests.

\section{Author details}

${ }^{1}$ National Clinical Research Center for Mental Disorders, Department of Psychiatry, and China National Technology Institute on Mental Disorders, The Second Xiangya Hospital of Central South University, Changsha 410011, Hunan, China. ${ }^{2}$ Qingdao Mental Health Center, Qingdao 266034, Shangdong, China. ${ }^{3}$ Shandong Mental Health Center, 49 East Wenhua Road, Jinan 250014, Shandong, China. ${ }^{4}$ Clinical Nursing Teaching and Research Section, The Second Xiangya Hospital, Central South University, Changsha 410011, Hunan, China. ${ }^{5}$ Center for Medical Genetics and School of Life Sciences, Central South University, Changsha 410078, Hunan, China.

Received: 28 June 2020 Accepted: 21 January 2021

Published online: 01 February 2021

\section{References}

1. Psychiatric A. Diagnostic and statistical manual of mental disorders, ffth edition (DSM-V). Arlington: American Psychiatric Publishing; 2013.

2. Hansen SN, Schendel DE, Parner ET. Explaining the increase in the prevalence of autism spectrum disorders: the proportion attributable to changes in reporting practices. JAMA Pediatr. 2015;169(1):56-62.

3. Sandin S, Lichtenstein P, Kuja-Halkola R, Larsson H, Hultman CM, Reichenberg A. The Familial Risk of Autism. JAMA. 2014;311(17):1770-7.

4. Saroukhani S, Samms-Vaughan M, Lee M, Bach MA, Bressler J, Hessabi M, et al. Perinatal factors associated with autism spectrum disorder in Jamaican children. J Autism Dev Disord. 2019:50(9):3341-57.

5. Hadjkacem I, Ayadi H, Turki M, Yaich S, Khemekhem K, Walha A, et al. Prenatal, perinatal and postnatal factors associated with autism spectrum disorder. J Pediatr. 2016;92(6):595-601.

6. Getahun D, Fassett MJ, Peltier MR, Wing DA, Xiang AH, Chiu V, et al. Association of Perinatal Risk Factors with autism Spectrum disorder. Am J Perinatol. 2017;34(3):295-304

7. Froehlich-Santino W, Londono Tobon A, Cleveland S, Torres A, Phillips J, Cohen $B$, et al. Prenatal and perinatal risk factors in a twin study of autism spectrum disorders. J Psychiatr Res. 2014:54:100-8.

8. Saleh AM, Dudenhausen JW, Ahmed B. Increased rates of cesarean sections and large families: a potentially dangerous combination. J Perinat Med. 2017:45(5):517-21.

9. Schieve LA, Tian LH, Baio J, Rankin K, Rosenberg D, Wiggins $L$, et al. Population attributable fractions for three perinatal risk factors for autism spectrum disorders, 2002 and 2008 autism and developmental disabilities monitoring network. Ann Epidemiol. 2014;24(4):260-6.

10. Curran EA, O'Neill SM, Cryan JF, Kenny LC, Dinan TG, Khashan AS, et al. Research review: birth by caesarean section and development of autism spectrum disorder and attention-deficit/hyperactivity disorder: a systematic review and meta-analysis. J Child Psychol Psychiatry. 2015:56(5):500-8.

11. HamadéA S, Medlej-HashimM,Hajj-MoussaE,Saadallah-ZeidanN,RizkF. Autismin children and correlates in Lebanon:apilotcase-controlstudy. J Res Health Sci. 2013;13(2):119-24

12. Maramara LA, He W, Ming X. Pre- and perinatal risk factors for autism spectrum disorder in a New Jersey cohort. J Child Neurol. 2014;29(12) 1645-51.

13. Al-Zalabani AH, Al-Jabree AH, Zeidan ZA. Is cesarean section delivery associated with autism spectrum disorder? Neurosciences. 2019:24(1):11-5.

14. Huberman Samuel M, Meiri G, Dinstein I, Flusser H, Michaelovski A, Bashiri A et al. Exposure to general anesthesia may contribute to the association between cesarean delivery and autism Spectrum disorder. J Autism Dev Disord. 2019;49(8):3127-35.

15. The L. Stemming the global caesarean section epidemic. Lancet. 2018;392: 10155. 
16. Feng $X L$, Wang $Y, A n L$, Ronsmans $C$. Cesarean section in the People's Republic of China: current perspective. J Womens Health. 2014;6:59-74.

17. Kolas T, Hofoss D, Daltveit AK, Nilsen ST, Henriksen T, Hager R, et al. Indications for cesarean deliveries in Norway. Am J Obstet Gynecol. 2003; 188(4):864-70

18. Barber EL, Lundsberg LS, Belanger K, Pettker CM, Funai EF, Illuzzi JL. Indications contributing to the increasing cesarean delivery rate. Obstet Gynecol. 2011;118(1):29-38.

19. Tully KP, Ball HL. Misrecognition of need: women's experiences of and explanations for undergoing cesarean delivery. Soc Sci Med. 2013;85:103-11.

20. Abebe Eyowas F, Negasi AK, Aynalem GE, Worku AG. Adverse birth outcome: a comparative analysis between cesarean section and vaginal delivery at Felegehiwot referral hospital, Northwest Ethiopia: a retrospective record review. Pediatr Health Med Ther. 2016;7:65-70.

21. Keag OE, Norman JE, Stock SJ. Long-term risks and benefits associated with cesarean delivery for mother, baby, and subsequent pregnancies: systematic review and meta-analysis. PLoS Med. 2018;15(1):e1002494.

22. Thavagnanam S, Fleming J, Bromley A, Shields MD, Cardwell CR. A metaanalysis of the association between caesarean section and childhood asthma. Clin Exp Allergy. 2008;38(4):629-33.

23. Polidano C, Zhu A, Bornstein JC. The relation between cesarean birth and child cognitive development. Sci Rep. 2017;7(1):11483.

24. Alvina $K$, Jodeiri Farshbaf M, Mondal AK. Long term effects of stress on hippocampal function: emphasis on early life stress paradigms and potential involvement of neuropeptide Y. J Neurosci Res. 2020.

25. Galland L. The gut microbiome and the brain. J Med Food. 2014;17(12): 1261-72.

26. Sucksdorff M, Lehtonen L, Chudal R, Suominen A, Gissler M, Sourander A. Lower Apgar scores and caesarean sections are related to attention-deficit/ hyperactivity disorder. Acta Paediatr. 2018;107(10):1750-8.

27. Curran EA, Dalman C, Kearney PM, Kenny LC, Cryan JF, Dinan TG, et al. Association between obstetric mode of delivery and autism spectrum disorder. JAMA Psychiatry. 2015;72(9):935-42.

28. Polo-Kantola P, Lampi KM, Hinkka-Yli-Salomaki S, Gissler M, Brown AS, Sourander A. Obstetric risk factors and autism spectrum disorders in Finland. J Pediatr. 2014;164(2):358-65.

29. Yip BHK, Leonard H, Stock S, Stoltenberg C, Francis RW, Gissler M, et al. Caesarean section and risk of autism across gestational age: a multi-national cohort study of 5 million births. Int J Epidemiol. 2017;46(2):429-39.

30. Yang XJ, Sun SS. Comparison of maternal and fetal complications in elective and emergency cesarean section: a systematic review and meta-analysis. Arch Gynecol Obstet. 2017;296(3):503-12.

31. Chien LN, Lin HC, Shao YH, Chiou ST, Chiou HY. Risk of autism associated with general anesthesia during cesarean delivery: a population-based birthcohort analysis. J Autism Dev Disord. 2015;45(4):932-42.

32. Sumikura H, Niwa H, Sato M, Nakamoto T, Asai T, Hagihira S. Rethinking general anesthesia for cesarean section. J Anesth. 2016:30(2):268-73.

33. Olutoye OA, Baker BW, Belfort MA, Olutoye OO. Food and Drug Administration warning on anesthesia and brain development: implications for obstetric and fetal surgery. Am J Obstet Gynecol. 2018;218(1):98-102.

34. DiMaggio CSL, Kakavouli A, Byrne MW, Li G. A retrospective cohort study of the association of anesthesia and hernia repair surgery with behavioral and developmental disorders in young children. J Neurosurg Anesthesiol. 2009; 21:286.

35. Wilder RT, Sprung J, Katusic SK, Barbaresi WJ, Mickelson C, Gleich SJ, et al. Early exposure to anesthesia and learning disabilities in a population-based birth cohort. Anesthesiology. 2009;110:796-804.

36. Small CJ, Stanley SA, Mitchell JR, Murphy K, Morgan DG, Ghatei MA, et al. Effects of chronic central nervous system administration of agouti-related protein in pair-fed animals. Diabetes. 2001;50:248-54.

37. Shen Y, Dong H, Lu X, Lian N, Xun G, Shi L, et al. Associations among maternal pre-pregnancy body mass index, gestational weight gain and risk of autism in the Han Chinese population. BMC Psychiatry. 2018;18(1):11.

38. Schmitz JC, Cholemkery H, Medda J, Freitag CM. Prä- und perinatale Risikofaktoren bei Autismus-Spektrum-Störung und Aktivitäts- und Aufmerksamkeitsstörung. Zeitschrift für Kinder- und Jugendpsychiatrie und Psychotherapie. 2017;45(3):209-17.

39. Nippita TA, Lee YY, Patterson JA, Ford JB, Morris JM, Nicholl MC, et al. Variation in hospital caesarean section rates and obstetric outcomes among nulliparae at term: a population-based cohort study. BJOG Int J Obstet Gynaecol. 2015;122(5):702-11.
40. Castellheim A, Lundstrom S, Molin M, Kuja-Halkola R, Gillberg C, Gillberg C. The role of general anesthesia on traits of neurodevelopmental disorders in a Swedish cohort of twins. J Child Psychol Psychiatry. 2018;59(9):966-72.

41. Lin EP, Lee JR, Lee CS, Deng M, Loepke AW. Do anesthetics harm the developing human brain? An integrative analysis of animal and human studies. Neurotoxicol Teratol. 2017;60:117-28.

42. Abe H, Sumitani M, Uchida K, Ikeda T, Matsui H, Fushimi K. Association between mode of anaesthesia and severe maternal morbidity during admission for scheduled caesarean delivery: a nationwide population-based study in Japan, 2010-2013. Br J Anaesth. 2018;120(4):779-89.

43. Devroe S, Van de Velde M, Rex S. General anesthesia for caesarean section. Curr Opin Anaesthesiol. 2015;28(3):240-6.

44. Hyde MJ, Modi N. The long-term effects of birth by caesarean section: the case for a randomised controlled trial. Early Hum Dev. 2012;88(12):943-9.

45. Lichtman Y, Sheiner E, Wainstock T, Segal I, Landau D, Walfisch A. Maternal history of recurrent pregnancy loss is associated with increased risk for long-term pediatric gastrointestinal morbidity in the offspring. Am J Reprod Immunol. 2018;79(2):e12799.

\section{Publisher's Note}

Springer Nature remains neutral with regard to jurisdictional claims in published maps and institutional affiliations.
Ready to submit your research? Choose BMC and benefit from:

- fast, convenient online submission

- thorough peer review by experienced researchers in your field

- rapid publication on acceptance

- support for research data, including large and complex data types

- gold Open Access which fosters wider collaboration and increased citations

- maximum visibility for your research: over $100 \mathrm{M}$ website views per year

At $\mathrm{BMC}$, research is always in progress.

Learn more biomedcentral.com/submissions 